\title{
Modification of Leather Split by In Situ Polymerization of Acrylates
}

\author{
Weixing Xu, Jianfei Zhou, Ya'nan Wang, and Bi Shi \\ Key Laboratory of Leather Chemistry and Engineering of Ministry of Education, Sichuan University, Chengdu 610065, China \\ Correspondence should be addressed to Bi Shi; sibitannin@vip.163.com
}

Received 6 June 2016; Revised 28 September 2016; Accepted 18 October 2016

Academic Editor: Ulrich Maschke

Copyright (C) 2016 Weixing Xu et al. This is an open access article distributed under the Creative Commons Attribution License, which permits unrestricted use, distribution, and reproduction in any medium, provided the original work is properly cited.

\begin{abstract}
Leather split, the byproduct of leather manufacture, possesses low utility value because it has loose weave of collagen fibers and weak mechanical strengths. Herein, a practical and convenient method for increasing strengths of leather split was developed by one-step in situ polymerization. The structures and properties of polyacrylate/leather split composites were systematically investigated. The results suggested the monomers with an $\alpha$-methyl and a proper straight-chain ester group, such as nBMA, can effectively modify the leather split. For leather split with a thickness of $1.6 \mathrm{~mm}$, the rational processes for preparation of polyacrylate/leather split composite are that monomer and split were stirred in a drum for 4 hours for full permeation and then the split was heated in anaerobic condition at $45^{\circ} \mathrm{C}$ for $30 \mathrm{~min}$. The tensile strength, tear strength, and elongation at break of the optimized PnBMA/split composite were $18.72 \mathrm{MPa}, 62.73 \mathrm{~N} / \mathrm{mm}$, and $46.02 \%$, respectively. With these mechanical properties, the split after modification can be well used as leather for making shoes, bags, gloves, and clothing.
\end{abstract}

\section{Introduction}

Leather processed from hides and skins is a kind of favorable material used for production of shoes, bags, gloves, clothing, and so forth. To meet these uses, leather should be split to a proper thickness in tanneries. As a result, the so-called leather split, the lower reticular layer of tanned leather, was obtained as byproduct of leather manufacture. Leather split has loose weave of collagen fibers and weak mechanical strengths. Usually, the tensile and tear strengths of split are weaker than half of the strengths of top-grain leather. Therefore, the utilization of split is largely limited [1,2].

Through the past decades, many methods have been tried to improve the properties of leather split. The most commonly used methods are retanning and coating. The retanning agents used include amino resin, vegetable tannin, and acrylate resin. The strength enhancement of split is extremely limited by retanning, although the fullness and softness may be improved. Coating can strengthen the split, especially using a polyurethane film [1-4]. However, due to the increase of thickness, hardness, and stiffness [4], this method is still not ideal enough [5].
Polyacrylate (PA), one of the most common chemical families of polymers, can be easily prepared through the traditional free radical polymerization [6]. Some previous work has found that acrylate monomers or prepolymers could be polymerized in pickled goat skins $[7,8]$, chrome-tanned sheep skin leather [9-11], chrome-tanned cattle hide leather [12-18], and chrome-tanned kangaroo skin leather [19-26]. All these studies focused on the retanning and filling effects of the polymerization for top-layer leathers which already had tight weave of collagen fibers and satisfactory mechanical properties; nevertheless, the influences of polymerization on leather strengths were not sufficiently concerned and investigated.

The applications of in situ polymerization of acrylate monomers on cotton, starch, cellulose, and wool [27-32] have been investigated rather extensively over the past several decades and appear to show much promise as a means of improving the properties of these natural products. It has been proved that in situ polymerization could produce retanning and filling effects in top-layer leather and therefore improve the evenness, hand feeling, and aesthetic of leather [9-18]. However, due to the tight collagen fiber network 
of papillary layer, the formation of interpenetrating network structure between PA and collagen fibers was limited, and thus strength enhancement effect was not obviously observed. Herein, thanks to the porosity of leather split, which can provide spaces for diffusion of acrylate monomers, it is expected that the in situ polymerization could be applied to the split, and such modification may result in improvement of properties of leather split without reduction of softness.

In this study, we try to use in situ polymerization of acrylate monomers to increase the strengths of chrome-tanned leather split. The porosity of leather split is beneficial to the uniform dispersion of acrylate monomers or prepolymers into leather split, which may favor the in situ polymerization and may avoid considerable increase of thickness, hardness, and stiffness. The porosity of leather split also provides the possibility of the formation of bicontinuous structure. On the basis of these speculations, the optimized in situ polymerization conditions of acrylate monomers in leather split were investigated in this study.

\section{Experimental}

2.1. Materials and Equipment. Chrome-tanned cattle hide leather splits with an average thickness of $1.6 \mathrm{~mm}$ were obtained from a local tannery in China. Methyl acrylate (MA), ethyl acrylate (EA), n-butyl acrylate (nBA), methyl methacrylate (MMA), ethyl methacrylate (EMA), n-butyl methacrylate (nBMA), azodiisobutyronitrile (AIBN), acetone, and ethyl alcohol were all chemical pure and purchased from Kelong Chemical Reagent Factory, Sichuan, China; isobutyl methacrylate (iBMA), tert-butyl methacrylate (tBMA), n-amyl methacrylate (nAMA), n-hexyl methacrylate (nHMA), n-essien methacrylate (nEMA), isooctyl methacrylate (iOMA), isodecyl methacrylate (iDMA), lauryl methacrylate (LMA), and stearyl methacrylate (SMA) were all chemical pure and purchased from Aladdin Industrial Corporation, Shanghai, China. The drum $(\varnothing 30 \mathrm{~cm})$ commonly used in leather processing trials was employed to stir acrylate monomer and leather split for penetration.

2.2. Pretreatment of Chrome-Tanned Leather Splits. The chrome-tanned leather splits were somewhat uneven in thickness and tightness. To make the experiment results comparable, all the leather split samples $(20 \mathrm{~cm} \times 20 \mathrm{~cm})$ were cut from butt area following back line. These selected samples were washed and wringed. Then, ethyl alcohol was used to dehydrate these samples three times $(2: 1, v / w)$. Finally, acetone was used to dehydrate these samples again $(2: 1, v / w)$ to make sure that the split samples were nearly waterless.

2.3. Preparation of PA/Leather Split Composites. Acrylate monomer with $3 \mathrm{wt} \%$ initiator AIBN (based on acrylate monomer weight) was dissolved in acetone to obtain $50 \mathrm{wt} \%$ acrylate monomer solution. The acrylate monomer solution and leather splits were put into drum $(2: 1, v / w)$ and run for a fixed time at room temperature. Then, the leather splits were taken out and heated in anaerobic condition at $45^{\circ} \mathrm{C}$ for $30 \mathrm{~min}$. After drying in the air, the in situ polymerized PA/leather split composites were prepared.
2.4. Measurements and Instruments. The morphologies of the PA/split composites were observed by scanning electron microscope (SEM, JSM-5900, JEOL, Japan) with an accelerating voltage of $5 \mathrm{kV}$. The thickness of composites was measured with a dial thickness gauge (MY-3130-A2, MingYu, Dongguan, China). The mechanical properties of the composites were tested with a universal testing machine (AI7000SN, GOTECH, Dongguan, China) according to Chinese national standards QB/T 2710-2005 and QB/T 2711-2005. The softness of composites was measured with a ball pressure softness tester (GT-303, GOTECH, Dongguan, China). The nitrogen content in composites was tested by nitrometer (K06, ShenSheng, China) according to Kjeldahl. The polymer contents in composites were calculated as $\left(1-P_{2} / P_{1}\right) \times 100 \%$, where $P_{1}$ and $P_{2}$ were nitrogen content in leather split and PA/leather split composite, respectively.

Smashed leather split powder was used to simulate the chemical reaction possibly taking place in the permeation process of monomers in leather split during drumming. The reaction conditions were exactly the same as the composite preparation except that leather split was replaced by split powder. After solid-liquid separation, oxygen was fed to the reaction solutions to terminate the living chains. Then, the intrinsic viscosities of the solution were measured using Ubbelohde viscometer (diluted, $0.3 \sim 0.4 \mathrm{~mm}$ ) to evaluate the prepolymerization degree of monomers during drumming approximately.

\section{Results and Discussion}

3.1. Effect of $\alpha$-Methyl in Acrylate Monomers on Mechanical Properties of PA/Leather Split Composites. The $\alpha$-methyl of the acrylate monomers directly affects molecular chain rigidity of polymer, and thus leads to the changes of molecule random coil size, crystallinity, glass transition, and mechanical properties of PA. Therefore, the fullness, softness, and mechanical properties of the PA/leather split composites will be influenced by the $\alpha$-methyl in acrylate monomers. Table 1 shows the mechanical properties and polymer contents of the composites. Generally, the in situ polymerization can remarkably increase tensile and tear strengths of the leather split, while its softness and elongation at break are decreased except for the one using nBMA as the reactant. In fact, the reduced average errors indicate the heterogeneity of splits has been improved. PA, as a kind of retanning agent, is commonly used in leather manufacturing and can improve the fullness and softness of leather because of its filling property among collagen fibers. But the mechanical properties of leather are little influenced by this retanning action because molecular chains of PA mainly combine with leather collagen fibers through hydrogen bonds and intermolecular forces. The remarkably increased mechanical properties of the leather split after in situ polymerization strongly suggest that the interpenetrating network structure has formed between PA and collagen fibers in leather split. This structure also will restrict the movement of collagen fibers, which reflects as the reductions of softness and elongation at break.

Meanwhile, it can be observed that, as for monomers with the same ester group, those without $\alpha$-methyl always provide 
TABLE 1: Physical properties and polymer contents of the PA/leather split composites.

\begin{tabular}{lccccc}
\hline Monomer & Tensile strength $(\mathrm{MPa})$ & Tear strength $(\mathrm{N} / \mathrm{mm})$ & Elongation at break $(\%)$ & Softness index & Polymer content $(\mathrm{wt} \%)$ \\
\hline None & $14.86( \pm 4.12)$ & $45.43( \pm 8.74)$ & $40.17( \pm 6.43)$ & $5.28( \pm 0.36)$ & 0 \\
MA & $36.80( \pm 1.17)$ & $81.59( \pm 3.31)$ & $18.90( \pm 2.24)$ & $2.17( \pm 0.20)$ & $20.73( \pm 0.65)$ \\
MMA & $31.90( \pm 2.21)$ & $72.66( \pm 4.44)$ & $21.10( \pm 2.10)$ & $3.19( \pm 0.21)$ & $19.91( \pm 0.58)$ \\
EA & $24.68( \pm 2.33)$ & $79.24( \pm 4.28)$ & $31.17( \pm 4.85)$ & $3.08( \pm 0.17)$ & $20.06( \pm 0.71)$ \\
EMA & $22.54( \pm 1.98)$ & $63.50( \pm 5.01)$ & $36.21( \pm 4.32)$ & $4.51( \pm 0.18)$ & $19.53( \pm 0.33)$ \\
nBA & $20.23( \pm 1.62)$ & $74.97( \pm 3.15)$ & $32.61( \pm 3.11)$ & $3.21( \pm 0.19)$ & $17.94( \pm 0.89)$ \\
nBMA & $18.72( \pm 1.41)$ & $62.79( \pm 3.77)$ & $46.02( \pm 3.48)$ & $5.41( \pm 0.17)$ & $17.36( \pm 0.60)$ \\
\hline
\end{tabular}

TABLE 2: Physical properties and polymer contents of the PMA/leather split composites.

\begin{tabular}{lccccc}
\hline Monomer & Tensile strength $(\mathrm{MPa})$ & Tear strength $(\mathrm{N} / \mathrm{mm})$ & Elongation at break $(\%)$ & Softness index & Polymer content $(\mathrm{wt} \%)$ \\
\hline None & $14.86( \pm 4.12)$ & $45.43( \pm 8.74)$ & $40.17( \pm 6.43)$ & $5.28( \pm 0.36)$ & 0 \\
MMA & $31.90( \pm 2.21)$ & $72.66( \pm 4.44)$ & $21.10( \pm 2.10)$ & $3.19( \pm 0.21)$ & $19.91( \pm 0.58)$ \\
EMA & $22.54( \pm 1.98)$ & $63.50( \pm 5.01)$ & $36.21( \pm 4.32)$ & $4.51( \pm 0.18)$ & $19.53( \pm 0.33)$ \\
nBMA & $18.72( \pm 1.41)$ & $62.79( \pm 3.77)$ & $46.02( \pm 3.48)$ & $5.41( \pm 0.17)$ & $17.36( \pm 0.60)$ \\
iBMA & $16.59( \pm 2.43)$ & $67.01( \pm 4.83)$ & $42.43( \pm 3.92)$ & $5.18( \pm 0.19)$ & $19.58( \pm 0.58)$ \\
tBMA & $18.10( \pm 1.68)$ & $68.29( \pm 4.21)$ & $38.65( \pm 4.25)$ & $4.19( \pm 0.16)$ & $19.91( \pm 0.35)$ \\
nHMA & $18.76( \pm 1.71)$ & $67.46( \pm 3.73)$ & $46.88( \pm 3.61)$ & $5.22( \pm 0.22)$ & $16.88( \pm 0.29)$ \\
iOMA & $19.04( \pm 2.03)$ & $56.66( \pm 4.67)$ & $48.98( \pm 3.77)$ & $4.53( \pm 0.14)$ & $15.27( \pm 0.48)$ \\
iDMA & $19.23( \pm 1.69)$ & $52.41( \pm 4.05)$ & $51.10( \pm 4.12)$ & $4.35( \pm 0.20)$ & $13.85( \pm 0.56)$ \\
LMA & - & - & - & - & - \\
SMA & - & - & - & & $35.45( \pm 0.29)$ \\
\hline
\end{tabular}

the composite with higher tensile and tear strengths, as well as lower softness and elongation at break. This should be due to the fact that the acrylate monomers or prepolymers without $\alpha$-methyl have smaller size and lesser steric hindrance, and thus they can form more uniform interpenetrating network structure with collagen fibers in the split. No significant difference in polymer content in the composites is found no matter the monomers with or without $\alpha$-methyl were used. But this actually implies that more PA is composed with collagen fibers when the monomers without $\alpha$-methyl are used in consideration of equivalent polymer chains. This might be another reason why the monomers without $\alpha$-methyl can increase tensile and tear strengths of the splits more effectively. Nonetheless, the decreased extent of softness is more considerable when the monomers without $\alpha$ methyl are used. Considering the fact that softness of leather products is more concerned by consumers, the monomers with $\alpha$-methyl are more suitable for this modification.

3.2. Effect of Branches in Methacrylate Monomers on Mechanical Properties of PA/Leather Split Composites. The mechanical properties and polymer contents of PA/leather split composites prepared by methacrylate monomers with different branches are shown in Table 2 . The composites prepared by LMA and SMA have much higher polymer contents than other samples but fail to dry in air. So their mechanical properties cannot be tested. The tensile and tear strengths of the composites may depend on three factors: mole percentage of PA in composite, molecular chain rigidity of PA, and entanglement of PA molecular chains with collage fibers of leather split. Due to the concurrent influences of these three factors, the changes of tensile and tear strengths are somewhat irregular although both of them are considerably increased after in situ polymerization. The softness index of the composites depends on both length of side-chain and polymer content. The sample made from MMA achieves a relatively higher polymer content, but its softness index is the lowest because of short side-chain of MMA. Additionally, iDMA has longer side-chain, but the softness index of PiDMA/leather split composite is also low because of low polymer content in the composite. Therefore, only the monomers that have a flexible branched chain and can easily deposit into leather split are capable of producing composite with increased mechanical strengths and a soft hand feeling. As a result, nBMA and nHMA achieve the most satisfactory comprehensive performances of composite in consideration of both softness and mechanical properties. In view of the fact that the price of nHMA is much higher than that of nBMA, nBMA is considered as the best choice.

\subsection{Formation of $n B M A$ Prepolymers during Drumming} and Its Effect on Mechanical Properties of PnBMA/Leather Split Composites. Before the acrylate monomers and leather splits were mixed in drum, the polymerization inhibitor in monomers had been removed, and the initiator had been added. So the monomers might polymerize slowly during the drumming even at room temperature, leading to the generation of a series of prepolymers. Leather split is a kind of three-dimensional structural material with porosity. Hence, it may take time for acrylate monomers to fully penetrate 
into leather split. The penetration of generated prepolymers during the drumming would be slower. Therefore, the prepolymerization degree of monomers in drum may largely affect the distribution of polymers after heating, as well as the properties of PA/leather split composite obtained.

In order to prove the occurrence of prepolymerization of acrylate monomers during drumming, the mixture of leather split powder and nBMA was used to simulate the reaction between leather split and acrylate monomer in drum, and viscosity change of the solution with drumming time was determined to characterize the degree of prepolymerization. There are many ways to determine the molecular weight of polymers. Among them, viscometry is a relatively quick and simple method. The viscosity-average molecular weight can be calculated by the Mark-Houwink-Sakurada (MHS) equation:

$$
[\eta]=K M_{v}^{\alpha},
$$

where $[\eta]$ is the intrinsic viscosity in $\mathrm{dL} / \mathrm{g}, M_{v}$ is the viscosityaverage molecular weight, and $K$ and $\alpha$ are viscometric constants for given solute-solvent system and temperature $[33,34]$.

However, the viscosity-average molecular weight of nBMA prepolymer in the reaction solution was too small to test at the standard concentration $(0.1 \mathrm{~mol} / \mathrm{L})$, and the standard $K$ and $\alpha$ was unsuitable for calculating the viscosityaverage molecular weight (only suitable for 1000000 $6000000 \mathrm{~g} / \mathrm{mol}$ ) [35]. As a result, the exact viscosity-average molecular weight could not be tested and could be only characterized by $\eta_{\mathrm{sp}} / c\left(\eta_{\mathrm{sp}}\right.$ is the specific viscosity, $c$ is the concentration of solution). $\eta_{\mathrm{sp}}$ can be calculated from the efflux times by

$$
\eta_{\mathrm{sp}}=\frac{t-t_{0}}{t_{0}}
$$

where $t$ is the efflux time of the solution and $t_{0}$ is the efflux time of pure solvent [33].

Figure 1 shows the change of $\eta_{\mathrm{sp}} / c$ with volume by volume concentration of poly(n-butyl methacrylate) (PnBMA) (2), which was measured by Ubbelohde viscometer at $25^{\circ} \mathrm{C}$. It is obvious that $\eta_{\mathrm{sp}} / c$ increases with drumming time, indicating the propagation of polymer chains. The straight fitting lines $(1 \mathrm{~h} \sim 12 \mathrm{~h})$ show that the prepolymers mainly exist as short chains without coiling, while the cures $(16 \mathrm{~h} \sim 24 \mathrm{~h})$ imply the prepolymer chains coil with each other. Generally, all the results demonstrate that the prepolymerization takes place during the mixing process of leather split and nBMA in drum.

Therefore, the prepolymers instead of acrylate monomers might be the main reactants inside leather split during following heating process. The prepolymers with different molecular weights penetrated into leather split and reached different depths of the three-dimensional porous structure, which would affect the properties of PnBMA/leather split composite.

Figure 2 shows the mechanical properties and polymer contents of the PnBMA/leather split composites prepared during different drumming time. Tensile strength, tear strength, softness, and polymer content of the composites

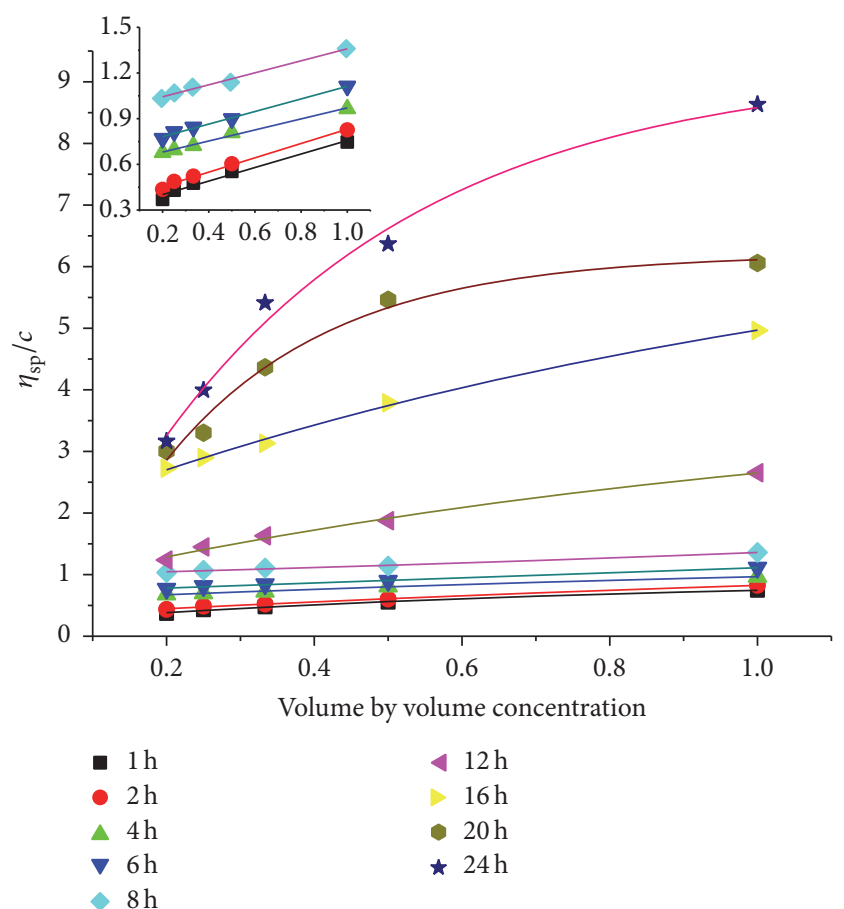

FIGURE 1: The relationship between $\eta_{\mathrm{sp}} / c$ and volume by volume concentration of PnBMA (the small graph at the top left corner is the enlargement of $1 \mathrm{~h} \sim 8 \mathrm{~h}$ samples).

increased firstly and then decreased with extending drumming time, while the elongation at break kept decreasing. In fact, the properties of modified leather split can be intuitively found even using a short time of drumming $(1 \mathrm{~h})$. The enhancements of strengths are mainly due to the formation of interpenetrating network structure between PA and collagen fibers in split. The precondition for forming the interpenetrating network structure is that the prepolymers of nBMA can sufficiently and uniformly penetrate into leather split during drumming. The extension of drumming time at initial stage $(1 \sim 4 \mathrm{~h})$ was favorable to penetration of prepolymers in leather split, and therefore the increased tensile and tear strengths of the composite were observed. Consequently, polymer content and softness of the composite were increased when drumming time was extended from $1 \mathrm{~h}$ to $4 \mathrm{~h}$. But with the extension of drumming time ( $6 \sim 24 \mathrm{~h})$, the molecular weights of prepolymers further increased, so that some of them failed to infiltrate into microstructures of split, which led to the reduction of polymer content, softness and strengths. The decrease of elongation at break should due to the fact that the movement, of collagen fibers in split was restricted when they were blended with PnBMA. In general, the rational drumming time is 4 hours before heating. A shorter time will cause insufficient permeation, and a longer time will lead to no significant improvement or even poorer properties of the composites.

Figure 3 shows the SEM photos of cross sections of PnBMA/split composites $(\times 2000)$. The in situ polymerization of nBMA in split after heating can efficiently enhance the aggregation of collagen fibers so as to increase strengths 


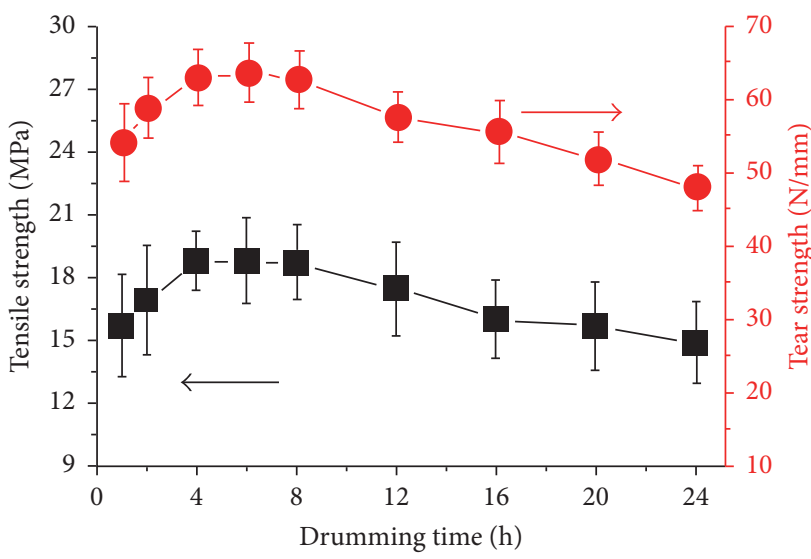

(a)

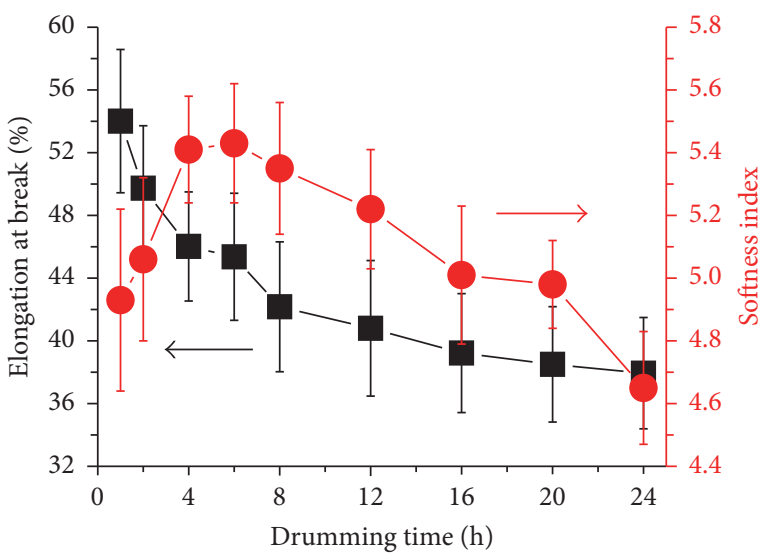

(b)

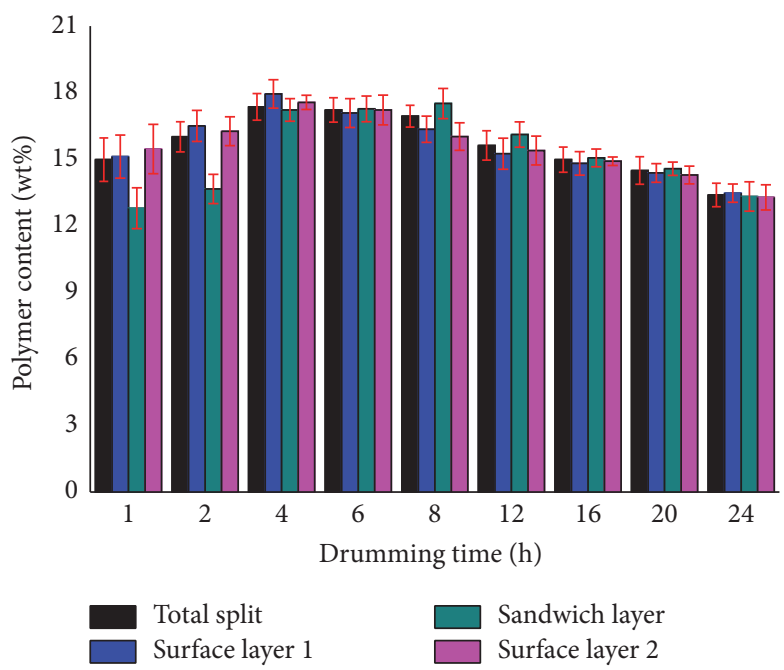

(c)

FIGURE 2: Effect of drumming time on physical properties and polymer contents of the PnBMA/Split composites.

of PnBMA/split composites. A satisfactory aggregation was achieved when nBMA and leather split were mixed in drum for $4 \mathrm{~h}$, and a further extension of drumming time did not lead to substantial change of the aggregation or even reduced the degree of aggregation, which is consistent with the results in Figure 2.

Furthermore, to detect the distribution of PnBMA in composites, the PnBMA/split composites were horizontally cut into 3 layers (cutting a $0.5 \mathrm{~mm}$ sheet from each face), and polymer content in each layer was determined. As shown in Figure 2(c), the polymer contents in sandwich layers were markedly lower than that in surface layers when nBMA and leather split were mixed in drum for 1 and 2 hours, which means that nBMA monomers and prepolymers were not fully penetrated into split. The polymer content became even in each layer with four hours of drumming, indicating that nBMA monomer and prepolymers had been uniformly distributed in split after drumming for 4 hours and were ready for in situ polymerization. The polymer content in sandwich layer was even higher than those in surface layers in the cases of drumming for more than 8 hours. This should be due to the fact that nBMA monomers and prepolymers in the surface might volatize more seriously than in sandwich layer in the initial stage of heating. These results once again suggest a period of 4 hours for penetration of nBMA monomers and prepolymers into leather split in drum is the best choice to achieve the most satisfactory in situ polymerization inside the split.

\section{Conclusions}

Tensile and tear strengths of leather split can be remarkably improved by in situ polymerization of acrylate monomers in split collagen fibers in proper conditions, probably because the interpenetrating network structure between PA and collagen fibers is constructed. The comprehensive performances of the modified leather split, including tensile strength, tear strength, softness, and elongation at break, largely depend on the monomers adopted. The monomers that have $\alpha$ methyl and a properly flexible side-ester chain around $4 \mathrm{C}$, like nBMA, achieve the best results. The distribution evenness of polymer in the split also considerably affects properties 

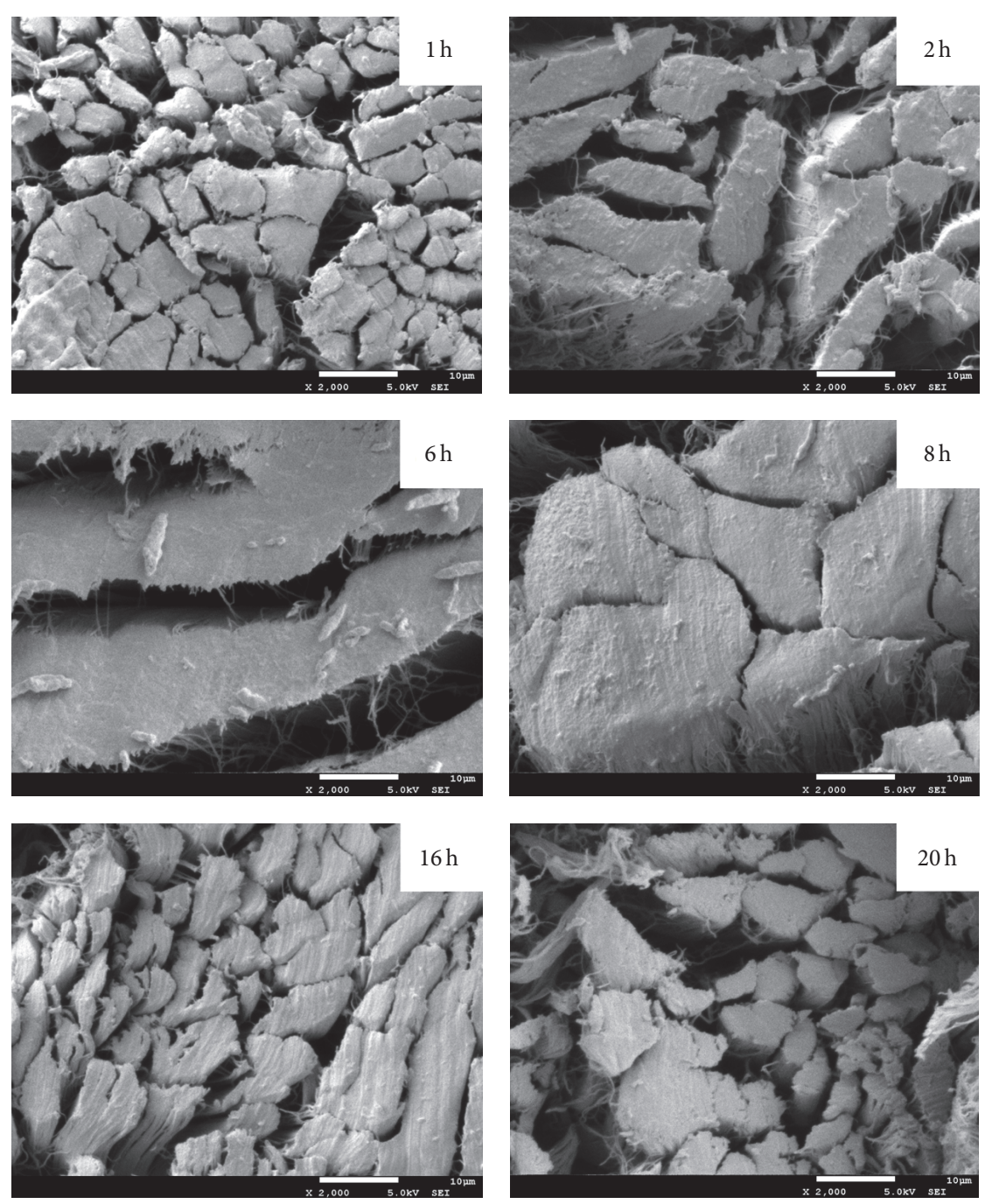
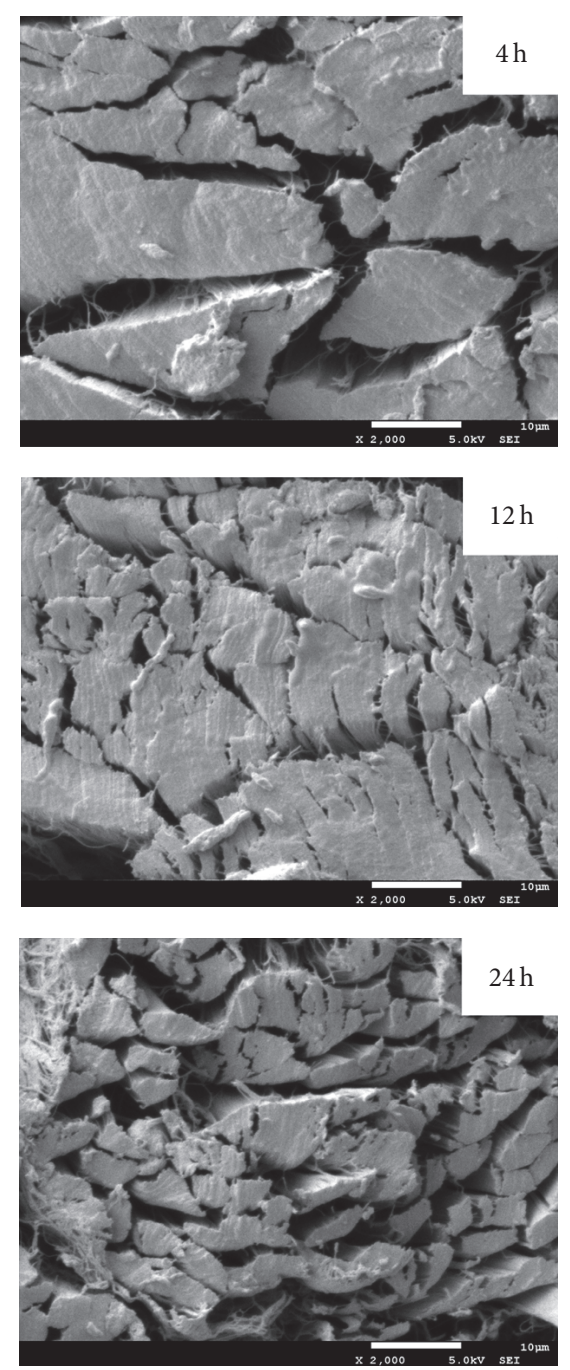

Figure 3: SEM photos of the cross-sections of the PnBMA/split composites $(\times 2000)$.

of the modified split. So monomer and its prepolymer need to fully penetrate into the split at room temperature firstly. Then, initiate the in situ polymerization by heating. The strengthened mechanical properties of the modified split promise that it has the potential to be applied in shoe, bag, and glove fabrications like common leather.

\section{Competing Interests}

The authors declare that they have no competing interests.

\section{Acknowledgments}

The financial support of this study was from the National Natural Science Foundation of China (Subject no. 21506129). The authors wish to thank all the testers of National Engineering Laboratory for Clean Technology of Leather Manufacture (Sichuan University) for their help and efforts in completing this research.

\section{References}

[1] Y. Shiga and Y. Hida, "Production of polyurethane-split leather laminate,” U.S. Patent No. 4,218,505, August 1980.

[2] R. Sutton, "Production of polyurethane film/split leather laminate," U.S. Patent No. 3,713,938, January 1973.

[3] H. Schaefer and P. Schaefer, U.S. Patent 4,581,261, 1986.

[4] P. Schaefer, "Leather, in particular split leather provided with a dressing as a process and apparatus for producing dressed leather," U.S. Patent No. 4,923,732. 8, May 1990.

[5] H. Yoneda, Y. Kimura, Y. Wakimoto, and K. Miyauchi, "Split leather product and manufacturing method therefor," U.S. Patent No. 2011/0020590, January 2011.

[6] M. P. Stevens, Polymer Chemistry, Oxford University Press, New York, NY, USA, 1990.

[7] X. He, R. Zeng, Z. Li, H. Cheng, and M. Chen, "The fiber weave network pattern effects to the shrinkage temperature of the animal skin," Leather Science and Engineering, vol. 2, article 8, 2012. 
[8] J. R. Rao, M. Kanthimathi, P. Thanikaivelan et al., "Picklefree chrome tanning using a polymeric synthetic tanning agent for cleaner leather processing," Clean Technologies and Environmental Policy, vol. 6, no. 4, pp. 243-249, 2004.

[9] C. Kaldirimci and N. Bas, "Radiation-initiated graft polymerization of methyl acrylate onto chrome-tanned sheepskin," Radiochemical and Radioanalytical Letters, vol. 53, p. 69, 1982.

[10] G. Schmidt and P. Meurer, "Method of producing a split leather, especially for automotive applications subject to temperature and humidity fluctuations," U.S. Patent No. 5,269,814, December 1993.

[11] R. H. Doggett, Natick, and P. A. Plasse, "Impregnation of leather with polymer dispersion by application of pressure," U.S. Patent No. 3,245,832., April 1966.

[12] E. F. Jordan Jr., B. Artymyshym, A. L. Everett, M. V. Hannigan, and S. H. Feairheller, "Polymer-leather composites. I. Process and location study for the deposition of selected acrylate monomers by polymerization into chrome-tanned cattlehide," Journal of Applied Polymer Science, vol. 25, no. 11, pp. 2621-2647, 1980.

[13] E. F. Jordan Jr. and S. H. Feairheller, "Polymer-leather composites-2. kinetics of the deposition of selected acrylate monomers by polymerization into chrome-tanned cattlehide," Journal of Applied Polymer Science, vol. 25, no. 12, pp. 2755-2776, 1980.

[14] E. F. Jordan, R. J. Carroll, M. V. Hannigan, B. Artymyshyn, and S. H. Feairheller, "Polymer-leather composites. III. Morphology and water absorptivities of selected acrylic polymer-leather composite materials," Journal of Applied Polymer Science, vol. 26, no. 1, pp. 61-84, 1981.

[15] E. E. Jordan Jr., B. Artymyshyn, and S. H. Feairheller, "Polymerleather composites. IV. Mechanical properties of selected acrylic polymer-leather composites," Journal of Applied Polymer Science, vol. 26, no. 2, pp. 463-487, 1981.

[16] J. Carraher, E. Charles, and L. H. Sperling, Polymer Applications of Renewable-Resource Materials, Springer, Berlin, Germany, 1983.

[17] E. F. Jordan Jr., B. Artymyshyn, and S. H. Feairheller, "Polymerleather composites-6. mechanism of deposition of selected acrylate monomers by polymerization into 5-ounce chrometanned cattlehide," Journal of the American Leather Chemists Association, vol. 77, no. 7, pp. 332-357, 1982.

[18] E. F. Jordan, B. Artymyshyn, A. E. Everett, R. J. Carroll, M. V. Hannigan, and S. H. Feairheller, "Polymer-leather composites. VII. Morphological and mechanical-properties of selected acrylate-leather composite materials," Journal of American Leather Chemists Association, vol. 77, p. 508, 1982.

[19] A. H. Korn, S. H. Feairheller, and E. M. Filachione, "Graft polymerization. I. Preliminary results with acrylate esters," Journal of the American Leather Chemists Association, vol. 67, p. 111, 1972.

[20] A. H. Korn, M. M. Taylor, and S. H. Feairheller, "Graft polymerization. II. Factors affecting the graft polymerization of vinyl monomers onto chrome-tanned hide substance," JournalAmerican Leather Chemists Association, vol. 68, p. 224, 1973.

[21] E. H. Harris, M. M. Taylor, and S. H. Feairheller, "Graft polymerization. III. Some properties of the leather obtained from the graft polymerization of vinyl monomers onto chrometanned Nigerian hairsheep," Journal-American Leather Chemists Association, vol. 69, p. 182, 1974.

[22] M. M. Taylor, E. H. Harris, and S. H. Feairheller, "Graft polymerization-4. further studies of the initiation step in the graft polymerization of vinyl monomers onto chrome-tanned collagen," Journal of the American Leather Chemists Association, vol. 72, no. 8, pp. 294-312, 1977.

[23] H. A. Gruber, E. H. Harris, and S. H. Feairheller, "Graft polymerization. VI. Studies on proof of grafting and molecular weights of the isolated poly(methyl methacrylate) grafts," Journal of the American Leather Chemists Association, vol. 73, no. 9, pp. 410-421, 1978.

[24] E. H. Harris, H. A. Gruber, and M. M. Taylor, "Graft polymerization. VII. Novel source of reductant for graft polymerization of leather," Journal of the American Leather Chemists Association, vol. 75 , p. $6,1980$.

[25] H. A. Gruber, M. M. Taylor, E. H. Harris, and S. H. Feairheller, "Graft polymerization. VIII. Effect of changes of changes in the initiating system on the molecular-weight of graft copolymer in polymer-tanned leather," Journal of the American Leather Chemists Association, vol. 73, p. 530, 1978.

[26] M. M. Taylor, M. V. Hannigan, and E. H. Harris, "Graft polymerization. IX. Improved distribution of grafted polymers in side leather," Journal-American Leather Chemists Association, vol. 75, p. 245, 1981.

[27] D. S. Varma and V. Narasimhan, "Thermal behavior of graft copolymers of cotton cellulose and acrylate monomers," Journal of Applied Polymer Science, vol. 16, no. 12, pp. 3325-3339, 1972.

[28] L. A. Gugliemelli, W. M. Ollidene, and C. R. Russell, U.S. Patent 3,377,302, 1968.

[29] D. Trimnell, G. F. Fanta, and J. H. Salch, "Graft polymerization of methyl acrylate onto granular starch: comparison of the $\mathrm{Fe}^{+2} / \mathrm{H}_{2} \mathrm{O}_{2}$ and ceric initiating systems," Journal of Applied Polymer Science, vol. 60, no. 3, pp. 285-292, 1996.

[30] K. Pal, A. K. Banthia, and D. K. Majumdar, "Development of carboxymethyl cellulose acrylate for various biomedical applications," Biomedical Materials, vol. 1, no. 2, p. 85, 2006.

[31] S. Zhao, W. Zhang, F. Zhang, and B. Li, "Determination of Hansen solubility parameters for cellulose acrylate by inverse gas chromatography," Polymer Bulletin, vol. 61, no. 2, pp. 189196, 2008.

[32] T. Jellinek, U.S. Patent 4,631,226, 1986.

[33] Z. Zeng, L. Sun, W. Xue, N. Yin, and W. Zhu, "Relationship of intrinsic viscosity to molecular weight for poly (1, 4-butylene adipate)," Polymer Testing, vol. 29, no. 1, pp. 66-71, 2010.

[34] A.-A. A. Abdel-Azim, A. M. Atta, M. S. Farahat, and W. Y. Boutros, "Determination of intrinsic viscosity of polymeric compounds through a single specific viscosity measurement," Polymer, vol. 39, no. 26, pp. 6827-6833, 1998.

[35] A. E. Nesterov, Handbook on Physical Chemistry of Polymers: Properties of Polymer Solutions and Blends, Naukova Dumka, Kiev, Ukraine, 1984. 

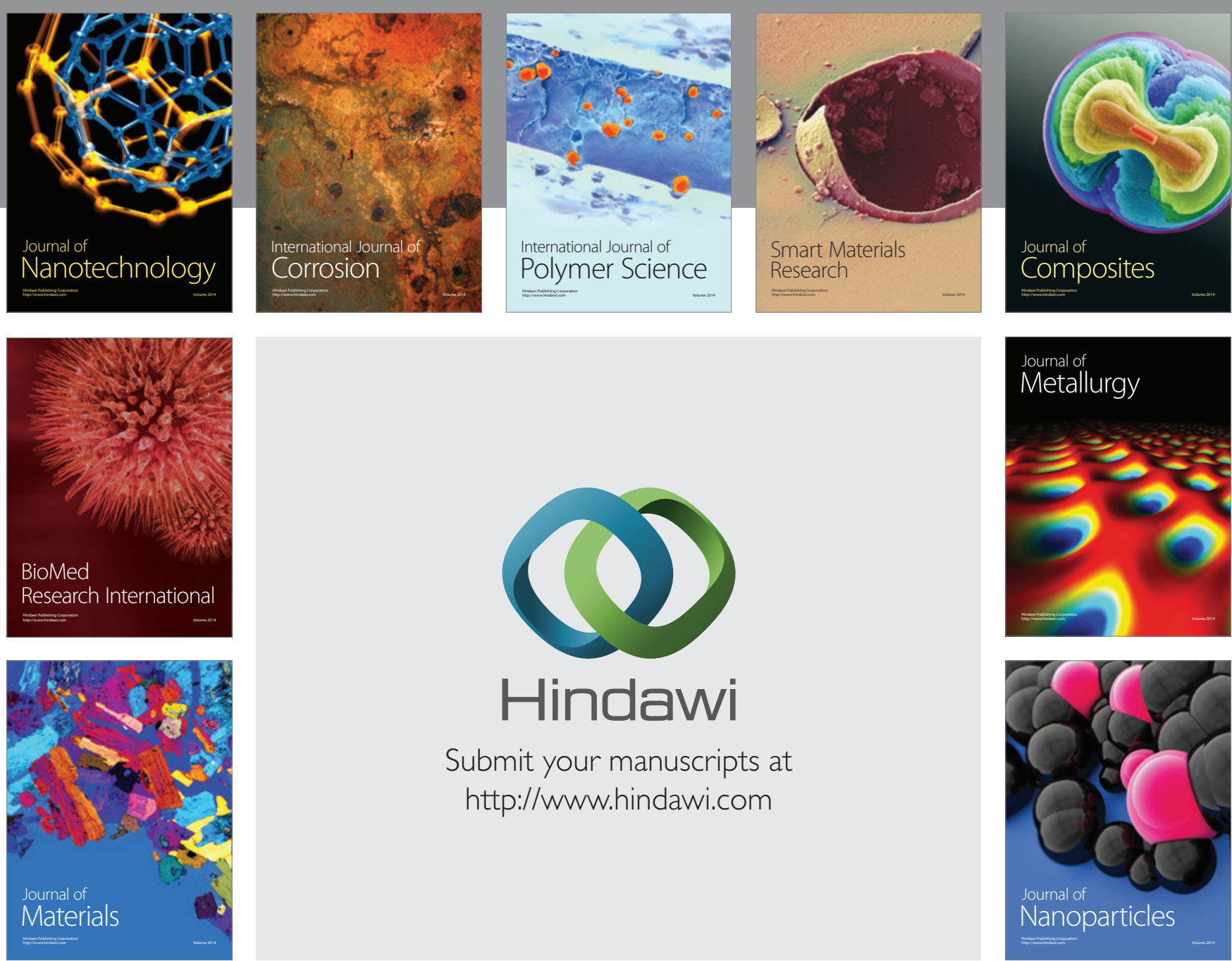

\section{Hindawi}

Submit your manuscripts at

http://www.hindawi.com

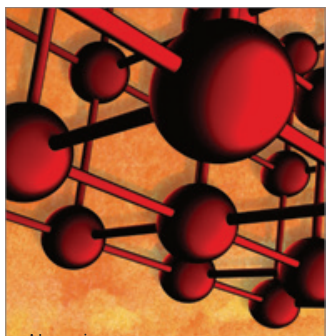

Materials Science and Engineering
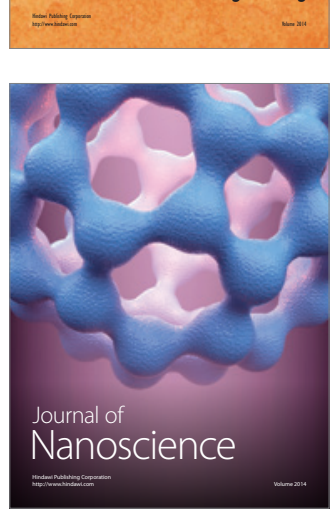
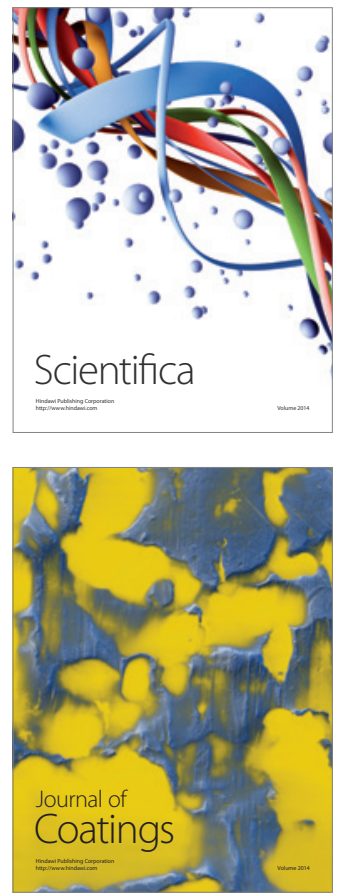
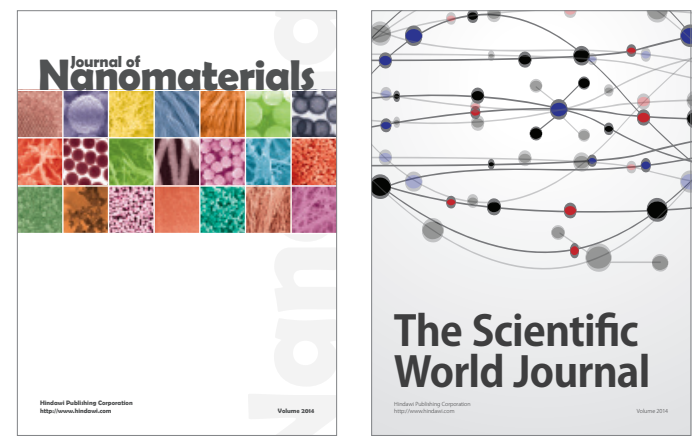

The Scientific World Journal
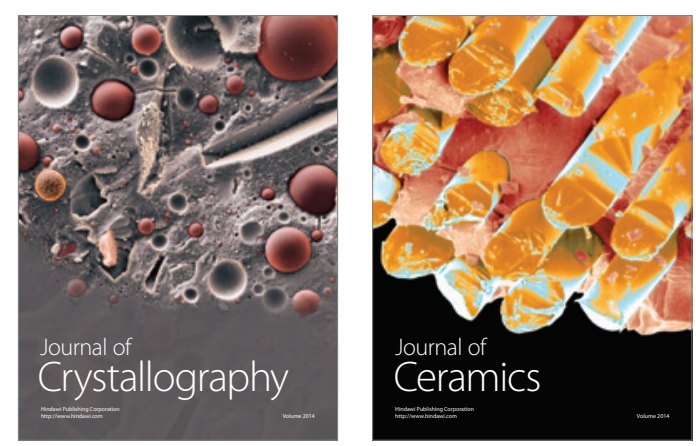
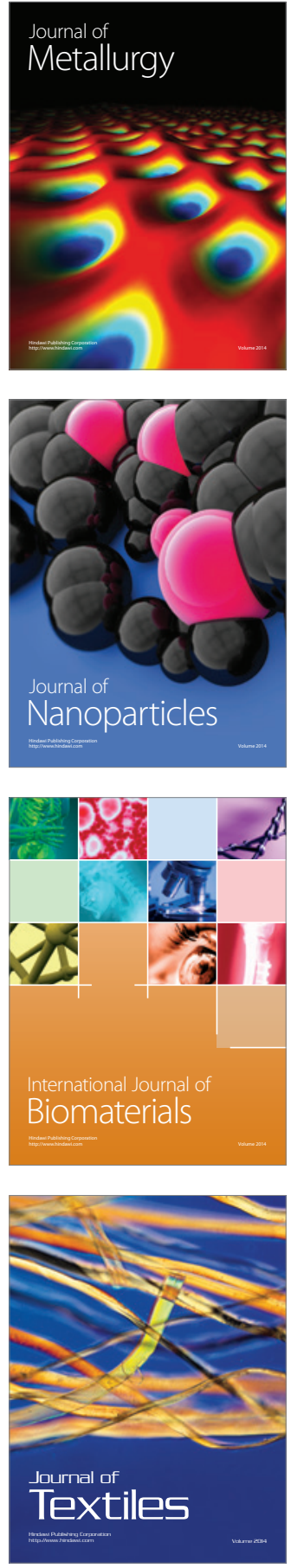